\title{
Kajian Tingkat Okupansi Kereta Api Penataran Relasi Sidoarjo-Malang
}

\author{
Uriansah Pratama, Abdul Hafiz Ardiansyah, Femmy Schouten \\ Politeknik Transportasi Darat Indonesia-STTD \\ Email: uriansah.pratama@ptdisttd.ac.id
}

\begin{abstract}
Abstrak
Tujuan penelitian ini adalah untuk menganalisis kajian tingkat okupansi kereta api penataran relasi Sidoarjo-Malang. Penelitian ini menggunakan jenis penelitian kualitatif dengan pendekatan analisis deskriptif. Data yang digunakan dalam penelitian ini berjenis data primer dan data sekunder. Analisis penelitian dilakukan dengann: 1) analisis kapasitas penumpang; 2) Analisis load factor; 3) Analisis kenyamanan tempat duduk dan penumpang berdiri; dan 4) Analisis pelayanan kereta api penataran susuai SPM. Berdasarkan hasil analisis luasan kereta saat ini adalah didapat nilai kenyamanan tempat duduk sebesar $0,48 \mathrm{~m} 2 /$ space. Artinya nilai tersebut sudah memenuhi nilai standar kenyamanan tempat duduk. Sedangkan untuk nilai kenyamanan tempat berdiri didapat nilai kenyamanan berdiri sebesar $0,170 \mathrm{~m} 2 /$ space. Artinya nilai tersebut belum memenuhi standar nilai kenyamanan berdiri. adapun luas ruang yang dapat dioptimalkan untuk penumpang berdiri sebesar 45 penumpang sesuai standar kenyamanan tempat berdiri; dan Berdasarkan hasil survey pada fasilitas penumpang KA Penataran diketahui rata-rata hampir memenuhi standar pelayanan pada 5 jenis pelayanan, dan masih belum memenuhi standar pelayanan pada 2 jenis pelayanan yakni Kenyamanan dan kesetaraan seperti tidak adanya fasilitas hand grip untuk penumpang berdiri dan kursi prioritas untuk penumpang disabilitas, ibu hamil, membawa balita, lanjut usia dan orang sakit.
\end{abstract}

Kata Kunci: Tingkat Okupansi, Kereta Api, Penataran Relasi.

\section{Abstract}

The purpose of this study was to analyze the study of the occupancy rate of the Sidoarjo-Malang relationship upgrading train. This research uses qualitative research with descriptive analysis approach. The data used in this study are primary data and secondary data. The research analysis was carried out by: 1) passenger capacity analysis; 2) Load factor analysis; 3) Analysis of seat and standing passenger comfort; and 4) Analysis of upgrading train services according to SPM. Based on the results of the analysis of the current area of the train, it is found that the comfort value of the seat is $0.48 \mathrm{~m} 2 /$ space. This means that this value already meets the standard value of seat comfort. As for the value of standing comfort, the value of standing comfort is $0.170 \mathrm{~m} 2 /$ space. This means that this value does not 
meet the standard of standing comfort value. as for the space that can be optimized for standing passengers of 45 passengers according to the standard of standing comfort; and Based on the survey results on the Penataran Train passenger facilities, it is known that on average they almost meet service standards for 5 types of services, and still do not meet service standards for 2 types of services, namely comfort and equality such as the absence of hand grip facilities for standing passengers and priority seats for passengers. disabilities, pregnant women, carrying toddlers, the elderly and the sick.

Keywords: Occupancy Rate, Train, Upgrading Relations.

\section{A. PENDAHULUAN}

Sektor transportasi memiliki peranan yang sangat penting dalam jaringan pelayanan mobilitas penumpang yang berkembang secara dinamis. Transportasi juga berperan dalam mendukung, mendorong, dan menunjang segala aspek kehidupan baik dalam bidang ekonomi, politik, sosial, budaya, maupun pertahanan dan keamanan. perkembangan suatu daerah tidak dapat dipisahkan dari sektor transportasi, secara tidak langsung akan sangat mempengaruhi tatanan kota secara keseluruhan dan juga mencakup segala aspek dalam kehidupan masyarakat.

Kereta api adalah sarana transportasi yang memiliki tenaga gerak, baik berjalan sendiri ataupun dirangkaikan dengan sarana lainnya, yang bergerak di atas rel. Dari definisi tersebut dapat ditarik kesimpulan bahwa kereta api memiliki beberapa keunggulan. Salah satunya adalah karakteristik Kereta Api yang memiliki kapasitas angkut dalam jumlah yang besar baik penumpang maupun barang.

Dalam penyelenggaraan angkutan kereta api harus memberi pelayanan dengan tingkat keselamatan, keamanan, ketepatan dan kenyamanan yang tinggi, maka dari itu prasarana dan sarana Kereta Api yang dioperasikan harus mempunyai kehandalan yang tinggi dan memenuhi persyaratan keselamatan yang tinggi agar Kereta Api sebagai alat transportasi selalu dalam kondisi siap operasi dan secara teknis layak untuk di operasikan.

Kondisi perkeretaapian nasional saat ini terus melakukan penataan dan perubahan baik dari segi sarana prasarana maupun SDM-nya, semua ini tentunya akan meningkatkan kinerja layanan kereta api kepada masyarakat. Agar kereta Api dapat bersangin dengan moda lain dan menjadi moda transportasi yang menjadi pilihan masyarakat dengan selamat, aman, nyaman, cepat dan lancar, tertib dan teratur, efisien serta menunjang pemerataan, pertumbuhan, stabilitas, pendorong, dan pengerak pembangunan nasional.

Perkembangan dalam bidang transportasi terutama kereta api sangat mempengaruhi kehidupan masyarakat dalam menjalankan aktivitasnya sehari- hari. Sebagai sarana pengangkut manusia, transportasi ini menjadi salah satu pilihan yang diminati oleh masyarakat umum. Permintaan pelayanan jasa kereta api semakin meningkat dari waktu ke waktu.

Salah satu moda transportasi favorit masyarakat di Jawa Timur diantaranya kereta api. Contohnya Kereta Api Penataran merupakan kereta api lokal kelas ekonomi yang dioperasikan Daop 8 Surabaya sejak tahun 1971 dan sudah digunakan untuk melayani rute Surabaya Kota sampai Blitar dengan panjang lintas $189 \mathrm{KM}$ dan melewati 23 stasiun. Dan berdasarakan hasil data dari unit angkutan penumpang Daerah Operasi 8 Surabaya pada tahun 2014-2019 menunjukan rata-rata pertambahan volume penumpang KA lokal Penataran sebesar 10,2\%. Serta mengalami peningkatan jumlah penumpang di setiap tahunnya. Dengan tingginya okupansi atau perbandingan jumlah tiket terjual dengan jumlah kapasitas tempat 
duduk serta berdasarkan hasil survey penumpang di Kereta Api Lokal Penataran ketahui sebanyak $16 \%$ penumpang pernah beralih moda karna tidak mendapatkan tiket KA lokal Penataran. sehingga dengan rata- rata okupansi di atas $100 \%$ menyebabkan banyak penumpang tiket tanpa kursi atau berdiri didalam KA Penataran yang berada dibordes atau sambungan antara kereta yang dapat membahayakan penumpang apabila terjadi suatu insiden.

Dalam kajian evaluasi kinerja operasional KA Penataran ini penulis menemukan permasalahan kurang optimalnya pelayanan angkutan penumpang sesuai dengan standar pelayanan minimum penumpang didalam kereta, yaitu diantaranya: 1) Okupansi atau load factor penumpang pada KA Penataran relatif tinggi terutama pada lintas lintas SidoarjoMalang; dan 2) Factor Keamanan dan kenyamanan penumpang berdiri di dalam kereta mengingat rute KA Penataran yang relatif panjang.

\section{B. TINJAUAN PUSTAKA}

\section{Aspek Legalitas}

Undang - Undang Nomer 23 Tahun 2007 Tentang Perkeretaapian teridri dari: 1) Pasal 1, Perkeretapian adalah satu kesatuan yang terdiri atas prasarana, sarana, sumber daya manusia, serta norma, kriteria, persyaratan dan prosedur untuk penyelenggaraan transportasi kereta api. Sarana Perkeretaapian adalah kendaraan yang dapat bergerak di jalan rel; 2) Pasal 3. Perkeretaapuan diselenggarakan dengan tujuan untuk memperlancar perpindahan orang atau barang secara massal dengan selamat, aman, nyaman, cepat dan lancar, tepat, tertib dan teratur, efesien, serta menunjang pemerataan, pertumbuhan, stabilitas, pendorong, dan penggerak pembangunan nasional; c) Pasal 27. Pengoperasian sarana perkeretaapian wajib memenuhi standar kelaikan operasi sarana perkeretaapian; d) Peraturan Pemerintah Nomer 72 tahun 2019 Tentang Lalu Lintas Dan Angkutan Kereta Api; e) Pasal 2. Angkutan kereta api dilaksanakan pada jaringan jalur kereta api dalam lintas pelayanan kereta api yang membentuk jaringan pelayanan perkertaapian terdiri atas Jaringan pelayanan perkeretaapian antarkota; dan Jaringan pelayanan perkerataapian perkotaan; f) Pasal 9. Jaringan pelayanan perkeretaapian antarkota diselenggarakan dengan ciri - ciri pelayanan: Menghubungkan beberapa stasiun antarkota, Tidak menyediakan layanan penumpang bediri, Melayani penumpang tidak tetap, Memiliki jarak dan waktu tempuh, Memilki frekuensi kereta api sedang atau rendah; dan Melayani kebutuhan angkutan penumpang dan barang antarkota; g) Pasal 15. Jaringan pelayanan perkeretaapian perkotaan diselanggarakan dengan kriteria pelayanan: Menghubungkan beberapa stasiun diwilayah perkotaan, Melayani penumpang berdiri, Memiliki sifat perjalanan ulang alik atau komuter, Melayani penumpang tetap, Memiliki jarak dan waktu tempuh pendek; dan Melayani kebutuhan angkutan penumpang didalam kota dan dari daerah sub-urban menuju pusat kota atau sebaliknya.

Peraturan Menteri Perhubungan Nomer 63 Tahun 2019 Tentang Standar Pelayanan Minimum Angkutan Orang Dengan Kereta Api pada Pasal 1, Standar pelayan minimum yang selanjutnya disingkat SPM adalah ukuran pelayanan yang harus dipenuhi oleh penyedia layanan dalam memberikan pelayanan kepada pengguna jasa, yang harus dilengkapi dengan tolak ukur yang dipergunakan sebagai pedoman penyelenggaraan pelayanan dan acuan penilain kualitas pelayanan sebagai kewajiban dan janji penyedia layanan kepada masyarakat dalam rangka pelayanan yang berkualitas, cepat, mudah, terjangkau dan terukur.

SPM Angkutan Orang Dengan Kereta Api adalah SPM yang diperuntukan bagi layanan penumpang kereta api, Perkeretaapian Perkotaan adalah perkeretaapian yang melayani perpindahan orang diwilayah perkotaan dan/atau perjalanan ulang alik, dan Penumpang Dengan Kebutuhan Khusus adalah penumpang karena kondisi fisiknya dan/atau permintaan khusus penumpang yang memerlukan.

Fasilitas dan perlakuan khusus, seperti penyandang disabilitas, lanjut usia, wanita hamil, 
menggendong anak dan orang sakit. Standar Pelayanan Minimum Angkutan Orang Dalam Perjalanan Kereta Api. Tempat duduk merupakan fasilitas untuk pengguna jasa angkutan kereta api untuk duduk didalam kereta selama perjalanan dengan jenis pelayanan keamanan dan kenyamanan kereta api perkotaan memiliki tolak ukur, seperti: Tempat duduk harus dengan kontruksi tetap yang mempunyai sandaran, Tempat duduk minimal $20 \%$ dari spesifikasi teknis kereta, dan Ruang untuk mengangkut penumpang berdiri maksimum $1 \mathrm{~m} 2$ untuk 6 orang.

Fasilitas Pegangan Penumpang merupakan fasilitas untuk penumpang berdiri didalam kereta selama perjalanan berupa hand rail dan hand grip yang harus tersedia di kerata api perkotaan. Fasilitas bagi penumpang berkebutuhan khusus berupa kursi prioritas yang dilengkapi dengan striker petunjuk dan edukatif edukatif di kereta api perkotaan memiliki tolak ukur: Tersedia kursi prioritas yang dilengkapi striker petunjuk dan edukatif Minimal 12(duabelas) tempat duduk dalam satu kereta.

\section{Aspek Teori}

Dalam mendukung penelitian dapat digunakan parameter dan teori diantaranya sebagai berikut: 1) Menurut Salim (2000), Transportasi adalah kegiatan pemindahan barang (muatan) dan penumpang dari suatu tempat ke tempat lain; 2) Menurut Tamin (1997), Transportasi adalah suatu sistem yang terdiri dari prasarana/sarana dan sistem pelayanan yang memungkinkan adanya pergerakan keseluruhan wilayaj sehingga terakomodasi mobilitas penduduk, dimungkinkan adanya pergerakan barang dan kemungkinan akses ke semua wilayah.

Menurut Parasuraman (1990), baik buruknya kualitas jasa sangat bergantung pada penilaian pengguna terhadap jasa yang dirasakan dalam konteks yang diharapkan. Jadi kualitas jasa dapat didefinisikan sebagai tingkat ketidaksesuaian antara apa yang diharapkan dengan apa yang dirasakan. Kepuasan pengguna jasa adalah tingkat perasaan seseorang setelah membandingkan kinerja(hasil) yang dirasakan dengan yang diharapkan.

Menurut Wibowo (2003), ada dua macam faktor yang memberikan kontribusi terhadap peningkatan jumlah pengguna angkutan umum, yaitu: faktor eksternal yang meliputi: pertumbuhan populasi, pertumbuhan ekonomi dan lapangan pekerjaan, perubahan bentuk kota, peralihan moda transportasi. Faktor internal meliputi: perubahan tarif angkutan umum,kualitas pelayanan (ketepatan jadwal, papan informasi, tempat duduk, kebersihan kereta). Beberapa hal yang perlu diperhatikan berkaitan dengan kualitas pelayanan didalam kereta api Penataran antara lain: Ventilasi udara yang baik, ketersediaan tempat duduk yang nyaman, minimnya guncangan, penerangan yang memadai, penyejuk udara (AC), kebersihan, keleluasaan (tidak berdesakan) dan keamanan sangat diharapkan oleh pengguna KA Penataran

Parameter Kenyamanan Kereta Api Untuk mendapatkan nilai-nilai kenyamanan kereta api Penataran perlu dilakukan beberapa perhitungan mengenai parameter yang berpengaruh terhadap kenyamanan kereta api: 1) Total Kapasitas (Cv), kapasitas kendaraan adalah daya muat penumpang pada setiap kendaraan angkutan umum, baik duduk maupun berdiri; 2) Elemen Yang Berpengaruh Terhadap Kapasitas Kendaraan: a) Dimensi Kendaraan. Meliputi panjang dan lebar lantai. Elemen-elemen tersebut menentukan luas lantai kotor kendaraan (Ag); b) Ruang Berguna Kendaraan Luas bersih kendaraan (An) yang dipakai oleh penumpang, yaitu luas kotor dikurangi dinding tebal kendaraan, body pada ujung untuk clearance, di tikungan dan di area yang tidak dipakai penumpang (tempat masinis, tempat mesin, dan toilet umum); c) Tingkat Okupansi Penumpang. Nilai okupansi adalah perbandingan antara jumlah penumpang dengan kapasitas tempat duduk yang tersedia didalam kereta.

Waktu Tempuh. Waktu tempuh adalah waktu yang dibutuhkan oleh kereta api untuk 
menempuh suatu perjalanan dari stasiun awal keberangkatan sampai stasiun akhir tujuan. Dalam waktu tempuh juga termasuk waktu berjalan, waktu berhenti untuk menaikan/menurunkan penumpang, waktu berhenti karena sinyal tidak aman dan waktu penundaan karena hal teknis.

Waktu Henti. Menurut Directorat Jendral Perhubungan Darat (2002) besarnya waktu berhenti tiap kendaraan pada pemberhentian sepanjang rute akan mempengaruhi efesiensi dari sistem angkutan secara keseluruhan. Waktu menaikan dan menurunkan penumpang tidak semua sama, melainkan diperhitungkan berdasarkan kebutuhan.

Headway. Menurut Hendarto (2001) Headway adalah waktu antara kedatangan dua kendaraan yang berurutan disatu titik pada ruas jalan. Satuan headway adalah menit. Headway minimum dalam suatu jarak dalam suatu petak jalan/blok dapat dihitung menggunakan rumus headway dan dipengaruhi oleh sistem persinyalan yang digunakan pada jalur, petak blok terpanjang, dan kecepatan operasi sarana.

Stamformasi. Stamformasi kereta api merupakan susunan rangkain kereta api untuk melayani jalur tertentu. Susunan stamformasi disesuaikan dengan kebutuhan dan kemampuan jumlah rangkain yang mampu ditarik lokomotif. Grafik Perjalanan Kereta Api (GAPEKA). Grafik Perjalanan Kereta Api adalah pedoman pengaturan pelaksanaan perjalanan kereta api yang digambarkan dalam bentuk garis yang menunjukan stasiun, waktu, jarak, kecepatan, dan posisi perjalanan kereta api mulai dari berangkat, bersilang, bersusulan, dan berhenti yang digambarkan secara grafis untuk pengendalian perjalanan kereta api.

\section{METODE}

Penelitian ini menggunakan jenis penelitian kualitatif dengan pendekatan analisis deskriptif. Data yang digunakan dalam penelitian ini berjenis data primer dan data sekunder. Data primer diperoleh dari okupansi Kereta Api Penataran dan survey fasilitas pelayanan kereta api penataran, sedangkan data sekunder diperoleh dari data spesifikasi kereta api penataran dan jumlah penumpang kereta api penataran. Lokasi penelitian ini dilakukan di daerah operasi VIII Surabaya khususnya pada lintas Sidoarjo-Malang. Waktu yang dilaksanakan peneliti dalam melakukan penelitian yaitu pada saat melaksanakan Praktek Kerja Lapangan selama tiga bulan, yang dimulai pada tanggal 16 desember 2019 - 16 Maret 2020. Analisis penelitian dilakukan dengann: 1) analisis kapasitas penumpang; 2) Analisis load factor; 3) Analisis kenyamanan tempat duduk dan penumpang berdiri; dan 4) Analisis pelayanan kereta api penataran susuai SPM.

\section{HASIL DAN PEMBAHASAN}

\section{Analisis Kapasitas Kereta}

KA Penataran merupakan KA lokal ekonomi milik PT KAI Daerah Operasi 8 Surabaya yang beroperasi dengan relasi Surabaya Kota - Blitar pulang pergi dan Blitar - Gubeng. Dalam pelayanan terhadap penumpang, KA Penataran terdiri dari 1 lok , 6 kereta ekonomi dan 1 Kereta makan penumpang ekonomi. Dalam pengoperasianya KA penataran memiliki volume penumpang yang terbilang tinggi. Hal ini dapat dilihat dari tabel data volume penumpang KA Penataran dalam 5 tahun terakhir diantaranya:

Tabel 1. Data volume penumpang KA penataran dalam 5 tahun

\begin{tabular}{|c|c|}
\hline Tahun & Volume Penumpang \\
\hline 2014 & $1,498,682$ \\
\hline 2015 & $1,640,673$ \\
\hline 2016 & $1,756,980$ \\
\hline
\end{tabular}




\begin{tabular}{|l|l|}
\hline 2017 & $1,966,780$ \\
\hline 2018 & $2,156,478$ \\
\hline 2019 & $2,539,722$ \\
\hline
\end{tabular}

Sumber: data diolah

Dari data di atas menunjukan bahwa volume penumpang KA Penataran mengalami kenaikan volume jumlah penumpang disetiap tahunnya. Hal ini menunjukan bahwa KA Penataran dengan relasi Surabaya Kota - Blitar banyak peminatnya. Berikut merupakan data volume penumpang KA Penataran dalam 3 bulan terakhir yang dimulai dari GAPEKA baru 2019 yakni dari Desember 2019 - Febuari 2020.

Tabel 2. Data volume penumpang KA Penataran Desember 2019-Februari 2020

\begin{tabular}{|c|c|c|c|c|}
\hline NO KA & Relasi & $\begin{array}{c}\text { PNP } \\
\text { Desember }\end{array}$ & $\begin{array}{c}\text { PNP } \\
\text { Januari }\end{array}$ & $\begin{array}{c}\text { PNP } \\
\text { Febuari }\end{array}$ \\
\hline 447 & SB-BL & 38,727 & 35,702 & 35,021 \\
\hline 449 & SB-BL & 43,592 & 38,351 & 36,115 \\
\hline 450 & BL-SB & 36,134 & 34,630 & 34,508 \\
\hline 451 & SB-BL & 46,726 & 42,306 & 39,030 \\
\hline 452 & BL-SB & 30,158 & 28,426 & 27,164 \\
\hline 453 & SB-BL & 35,565 & 34,775 & 34,734 \\
\hline 454 & BL-SGU & 32,290 & 29,682 & 27,155 \\
\hline 456 & BL-SB & 23,384 & 19,971 & 18,177 \\
\hline
\end{tabular}

Sumber: data diolah

Dari tabel diatas dapat dilihat bahwa selama beroperasi dengan GAPEKA baru yakni dari bulan desember 2019 sampai febuari 2020 volume penumpang KA Penataran cukup tinggi, puncaknya pada bulan desember dikarenakan bersamaan dengan momen libur tahun baru dan natal sehingga mengalami lonjakan penumpang yang tinggi, khususnya pada KA Penataran 451 yang berangkat siang hari pukul 11:10 dari Surabaya adapun KA Penataran 456 memiliki jumlah terendah dikarenakan jadwal keberangkatan pada sore hari yakni pukul 17:57 dari blitar sehingga sampai Surabaya malam pukul 23:12 demand KA Penataran yang tinggi dikarenakan jam keberangkatan yang sesuai dengan minat penumpang.

\section{Analisis Faktor Muat (Load Factor)}

Analisis ini di maksudkan untuk mengukur kapasitas penumpang setiap kali perjalanan, sehingga dari data load factor, nantinya dapat diketahui apakah KA Penataran mampu mengangkut penumpang dalam kapasitas maksimal. Apabila ditinjau dari kepentingan pengguna jasa, nilai load factor yang rendah akan menyenangkan karena lebih leluasa dan longgar dalam tempat duduknya. Akan tetapi bagi pengusaha jasa transportasi load factor yang rendah dapat merugikan mereka karena kapasitas angkut tidak maksimal, untuk mengatahui nilai load factor KA Penataran menggunakan perhitungan load factor pada setiap kereta dari dua arah yakni, arah Surabaya-Blitar dan arah Blitar-Surabaya.

Berdasarkan data kapasitas kereta maka dapat dihitung hasil load factor dari KA Penataran ini didapat dengan cara membagi jumlah penumpang yang terangkut setiap bulannya dengan kapasitas daya angkut kereta dalam 1 rangkaian kereta api baik kapasitas tempat duduk maupun kapasitas berdiri. sehingga dari perhitungan ini akan di ketahui nilai load factor KA Penataran setiap bulannya, dengan rumus sebagai berikut: 


$$
\text { Load factor }=\frac{\text { jumlah penumpang }}{\text { kapasitas angkut }} \times 100 \%
$$

Pada analisis untuk mengatahui nilai load factor perbulan KA Penataran menggunakan data volume penumpang dari bulan desember 2019 sampai febuari 2020 ditinjau berdasarkan Gapeka baru 2019. Dalam menghitung load factor pada tiap KA Penataran Per bulannya yakni: 1) Diketahui terlebih dahulu tentang volume penumpang total per bulan untuk masing-masing arah. Misal pada tabel V.3 diketahui untuk KA nomer 447 volume total pada bulan januari 2020 adalah 35.702 penumpang; 2) Menghitung rata-rata data volume penumpang perhari dengan cara membagi volume penumpang per bulan untuk per satu rangkaian kereta dengan jumlah hari dalam bulan tersebut. Berikut hasil analisis nilai load factor KA Penataran dengan awal perjalanan dari arah Surabaya Kota - Blitar yakni dengan Nomer KA (447, 449 451, dan 453).

Tabel 3. Load Factor KA Penataran 447

\begin{tabular}{|l|c|c|c|c|l|}
\hline \multirow{2}{*}{ Tahun } & Bulan & $\begin{array}{c}\text { Kapasitas } \\
\text { Angkut }\end{array}$ & $\begin{array}{c}\text { Volume } \\
\text { Penumpang Per } \\
\text { bulan }\end{array}$ & $\begin{array}{c}\text { Rata-rata } \\
\text { penumpang per } \\
\text { hari }\end{array}$ & $\begin{array}{l}\text { Nilai Load } \\
\text { Factor }\end{array}$ \\
\hline 2019 & Desember & 29,574 & 38,727 & 1249 & $131 \%$ \\
\hline \multirow{2}{*}{2020} & Januari & 29,547 & 35,702 & 1152 & $121 \%$ \\
\cline { 2 - 6 } & Februari & 27,666 & 35,021 & 1208 & $127 \%$ \\
\hline \multicolumn{7}{|c|}{ Nilai rata-rata load factor perbulan } & $126 \%$ \\
\hline
\end{tabular}

Sumber: data diolah

Dari data tabel diatas diketahui nilai load factor rata-rata kedua arah terendah pada KA Penataran nomer 456 dikarenakan jadwal perjalanan terakhir dari arah blitar, sedangkan nilai load factor rata-rata tertinggi pada KA Penataran nomer 451 dengan jadwal perjalanan pagi hari dari arah Surabaya. Adapun nilai load factor yang rendah diartikan bahwa selalu tersedia tempat duduk bagi penumpang, dan perjalanan lebih nyaman. Dan dari analisis di atas dapat dilihat pada kondisi dilapangan yang menggambarkan bahwa rata-rata KA Penataran memiliki load factor yang tinggi.

\section{Analisis Kenyamanan Tempat Duduk dan Tempat Berdiri}

Salah satu parameter kinerja angkutan kereta api penumpang berdasarkan Peraturan Menteri Perhubungan No. 63 Tahun 2019 adalah tersedianya tempat duduk dan tempat berdiri penumpang yang sesuai dengan standar tempat duduk yaitu r (kenyamanan tempat duduk) 0,35-0,5 m2/space. dan berdiri (kenyamanan tempat berdiri) $\sigma$ 0,20-0,25 $\mathrm{m} 2 /$ space. untuk mengetahui kapasitas total $(\mathrm{Cv})$ KA Penataran harus diketahui terlebih dahulu berapa jumlah space tempat duduk $(\mathrm{m})$ dan jumlah space tempat berdiri $(\sigma)$. Untuk mengetahuinya maka dilakukan survey pengukuran terhadap satu unit kereta KA Penataran. Hasil dari survei pengukuran tersebut dapat dilihat pada gambar berikut ini: 


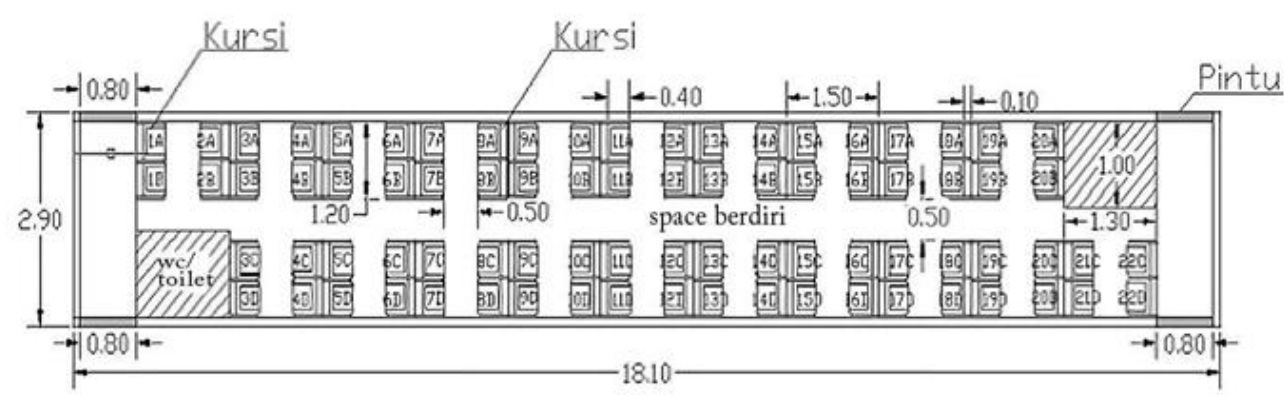

Gambar 1. Layout KA Penataran

Sumber: data diolah

Sesuai dengan keterangan tentang kapasitas tempat duduk yang telah tertera didalam kereta yaitu 106 tempat duduk, dan 53 kapasitas penumpang berdiri, maka dapat dicari nilai kenyamanan duduk (r) dan kenyamanan tempat berdiri, dari hasil perhitungan dapat diketahui bahwa kapasitas tempat berdiri yang ideal sesuai standar kenyamanan tempat berdiri adalah 45 penumpang.

\section{Analisis Fasilitas Pelayanan KA Penataran}

Analisis fasilitas pelayanan ini untuk mengetahui kondisi fasilitas pelayanan saat ini didapat secara observasi yakni melalui survey langsung didalam KA Penataran. Adapun yang menjadi obyek pada analisis ini sesuai dengan Peraturan Menteri Perhubungan Nomor 63 Tahun 2019 yaitu standar ukuran minimum pelayanan yang harus dipenuhi didalam kereta api,mencakup 5 aspek yaitu : keselamatan, keamanan, kenyamanan, kemudahan, dan kesetaraan.

Tabel 4. Hasil survey fasilitas pelayanan KA Penataran

\begin{tabular}{|c|c|c|c|c|c|c|}
\hline NO & $\begin{array}{c}\text { JENIS } \\
\text { PELAYANAN }\end{array}$ & URAIAN & TOLAK UKUR & ADA & TIDAK & $\underset{\text { I }}{\text { KONDIS }}$ \\
\hline \multirow{4}{*}{1} & \multirow{4}{*}{ Keselamatan } & \multirow{3}{*}{$\begin{array}{c}\text { Informasi dan Fasilitas } \\
\text { Keselamatan }\end{array}$} & APAR & $\checkmark$ & & SESUAI \\
\hline & & & Rem Darurat & $\checkmark$ & & SESUAI \\
\hline & & & Pemecah Kaca & $\checkmark$ & & SESUAI \\
\hline & & $\begin{array}{c}\text { Informasi dan Fasilitas } \\
\text { Kesehatan }\end{array}$ & $\begin{array}{l}\text { Perlengkapan } \\
\text { P3K }\end{array}$ & $\checkmark$ & & SESUAI \\
\hline \multirow[b]{3}{*}{2} & \multirow{3}{*}{ Keamanan } & Fasilitas Pendukung & $\begin{array}{l}\text { CCTV (min } \\
\text { 2/kereta) }\end{array}$ & $\checkmark$ & & SESUAI \\
\hline & & Petugas Keamanan & $\begin{array}{c}\text { Petugas } \\
\text { Kemanan (min } \\
\text { 1) }\end{array}$ & $\checkmark$ & & SESUAI \\
\hline & & $\begin{array}{l}\text { Informasi gngguan } \\
\text { keamanan }\end{array}$ & $\begin{array}{c}\text { Striker } \\
\text { pengaduan( } \\
\text { min 4) }\end{array}$ & $\checkmark$ & & SESUAI \\
\hline
\end{tabular}




\begin{tabular}{|c|c|c|c|c|c|c|}
\hline & & Lampu penerangan & $\begin{array}{c}\text { lampu dengan } \\
\text { intensistas } \\
\text { cahaya } 200 \text { lux }\end{array}$ & $\checkmark$ & & SESUAI \\
\hline \multirow{5}{*}{3} & \multirow{5}{*}{ Kenyamanan } & \multirow{2}{*}{$\begin{array}{l}\text { Tempat duduk dengan } \\
\text { kontruksi tetap yang } \\
\text { mempunyai sandaran }\end{array}$} & $\begin{array}{c}\text { Tempat duduk } \\
\text { minimal } 20 \% \\
\text { dar spesifikasi } \\
\text { kereta }\end{array}$ & $\checkmark$ & & SESUAI \\
\hline & & & $\begin{array}{c}\text { Ruang } \\
\text { penumpang } \\
\text { berdiri } \\
\text { maksimum } 1 \\
\mathrm{~m}^{2} \text { untuk } 6 \\
\text { orang }\end{array}$ & & $\checkmark$ & $\begin{array}{l}\text { TIDAK } \\
\text { SESUAI }\end{array}$ \\
\hline & & $\begin{array}{l}\text { Fasilitas Pengatur sirkulasi } \\
\text { udara }\end{array}$ & $\begin{array}{l}\text { AC / Kipas } \\
\text { angin }\end{array}$ & $\checkmark$ & & SESUAI \\
\hline & & $\begin{array}{l}\text { Fasilitas Pegangan } \\
\text { Penumpang Berdiri }\end{array}$ & $\begin{array}{l}\text { Hand Rail Dan } \\
\text { Hand Grip }\end{array}$ & & $\checkmark$ & $\begin{array}{r}\text { TIDAK } \\
\text { SESUAI }\end{array}$ \\
\hline & & Rak bagasi & Rak bagasi & $\checkmark$ & & SESUAI \\
\hline
\end{tabular}

Sumber: data diolah

a. Aspek Keselamatan

Pada aspek keselamatan KA Penataran telah memenuhi tolak ukur standar pelayanan minimum yakni tersedianya informasi dan fasilitas keselamatan yang berupa APAR, rem darurat, alat pemecah kaca dan petunjuk jalur evakuasi, dan juga terdapat informasi dan fasilitas kesehatan berupa perlengkapan P3K dalam keadaan sesuai standar pelayanan minimum.

\section{b. Aspek Keamanan}

Pada aspek kesalamatan telah memenuhi tolak ukur standar pelayanan yakni terdapat fasilitas pendukung berupa CCTV, informasi dan gangguan keamanan berupa striker pengaduan berisi tentang nomer telepon PPKA dan juga terdapat petugas keamanan yakni Polsuska yang bertugas untuk menjaga ketertiban dan keamanan penumpang.

\section{c. Aspek Kenyamanan}

Pada bagian aspek kenyamanan beberapa fasilitas yang terkait dengan kenyamanan penumpang seperti tempat duduk. Lampu penerangan, pendingin udara maupun rak bagasi dalam keadaan sesuai standar kenyamanan, sedangkan untuk fasilitas penumpang berdiri masih belum memenuhi standar pelayanan minium yakni tidak adanya fasilitas hand grip atau pegangan untuk penumpang berdiri.

\section{d. Aspek Kemudahan}

Pada aspek kemudahan belum memenuhi tolak ukur standar pelayanan minimum yakni belum tersedianya fasilitas informasi stasiun yang akan dilewati dan gangguan perjalanan dalam bentuk visual seperti papan informasi stasiun maupun LED, tetapi untuk fasilitas audio berfungsi dengan baik disetiap stasiun yang akan dilewati akan ada 
pengumuman melalui pengeras suara yang ada didalam KA Penataran.

\section{e. Aspek Kesetaran}

Untuk aspek kesetaran pada KA Penataran belum memenuhi standar pelayanan minum karna tidak tersedianya fasilitas untuk penumpang prioritas seperti tempat duduk priortas untuk penumpang disabilitas, ibu hamil, membawa balita, lanjut usia dan orang sakit. Dan tidak tersedianya fasilitas untuk tempat kursi roda bagi penumpang yang membawa kursi roda.

\section{E. KESIMPULAN}

Berdasarkan hasil pengamatan dan analisis yang telah dilakukan maka dapat disimpulkan bahwa: 1) Kondisi okupansi KA Penataran saat ini adalah rata-rata sebesar diatas $100 \%$ dan nilai load factor yang tinggi dimana hal tersebut membuktikan bahwa minat masyarakat yang tinggi menggunakan KA Penataran menyebabkan adanya penumpang berdiri dan ada yang tidak mendapatkan tiket; 2) Berdasarkan hasil analisis luasan kereta saat ini adalah didapat nilai kenyamanan tempat duduk sebesar $0,48 \mathrm{~m} 2 /$ space. Artinya nilai tersebut sudah memenuhi nilai standar kenyamanan tempat duduk. Sedangkan untuk nilai kenyamanan tempat berdiri didapat nilai kenyamanan berdiri sebesar $0,170 \mathrm{~m} 2 /$ space. Artinya nilai tersebut belum memenuhi standar nilai kenyamanan berdiri. adapun luas ruang yang dapat dioptimalkan untuk penumpang berdiri sebesar 45 penumpang sesuai standar kenyamanan tempat berdiri; 3) Dengan kondisi saat ini kapasitas angkut sebesar 106 tempat duduk dan 50\% untuk penumpang berdiri dari kapasitas tempat duduk atau 53 penumpang berdiri yang artinya okupansi standar saat ini sebesar $150 \%$ dalam satu kereta, dan berdasarkan hasil analisis standar kapasitas berdiri adalah sebesar 45 penumpang. Artinya kondisi standar okupansi saat ini belum memenuhi standar kenyamanan untuk penumpang berdiri sehingga penumpang didalam kereta tidak nyaman dan aman; dan 4) Berdasarkan hasil survey pada fasilitas penumpang KA Penataran diketahui rata-rata hampir memenuhi standar pelayanan pada 5 jenis pelayanan, dan masih belum memenuhi standar pelayanan pada 2 jenis pelayanan yakni Kenyamanan dan kesetaraan seperti tidak adanya fasilitas hand grip untuk penumpang berdiri dan kursi prioritas untuk penumpang disabilitas, ibu hamil, membawa balita, lanjut usia dan orang sakit.

\section{DAFTAR PUSTAKA}

Abbas, Salim. 2000. Manajemen Transportasi. Cetakan Pertama. Edisi Kedua. Ghalia Indonesia. Jakarta.

Agus, M.Z. 2017, “Analisis peningkatan KA Lokal Bandung Raya Guna Mengatasi Lonjakan Penumpang Pada Dua Jam Sibuk Pagi Di Stasiun Cicalengka - Cikemar”, KKW, A.Md. KA., Jurusan Perkeretaapian, Sekolah Tinggi Transportasi Darat, Bekasi, 2017.

Anonim ,1995, Urban Mass Transportation Planning. Mc.Graw-Hill International Edition.

Bijak, H.M. 2019, "Peningkatan Kinerja Pelayanan Kereta Api Ekonomi Lokal Cibatuan Guna Membantu Mobilitas Masyarakat", KKW, A.Md. KA., Jurusan Perkeretaapian, Sekolah Tinggi Transportasi Darat, Bekasi, 2019.

Parasuraman, 1994, "Reassessment of Expectations as a Comparison Standar in Measurung Service Quality: Implications for Future Research,. Journal of Marketing, Vol;. 58 (January), pp. 111- 124. 
Peraturan Menteri Perhubungan Republik Indonesia, Nomer 63 Tahun 2019 Tentang Standar Pelayanan Minimum Angkutan Orang Dengan Kereta Api, Jakarta, 2019

Peraturan Pemerintah Republik Indonesia, Nomer 72 tahun 2019 Tentang Lalu lintas dan Angkutan kereta Api, Jakarta, 2019.

Sekolah Tinggi Transportasi Darat, 2020, Laporan Umum Praktek Kerja Lapangan Daerah Operasi 8 Surabaya Lintas Sidoarjo-Malang, Tahun 2020, Bekasi, STTD

Sugeng, Hammam, 2018, "Analisa Kinerja KA Komuter Surabaya-Lamongan Performance Analysis KA Commuter Surabaya Lamongan)" UkaRsT VOL.2, NO. 2 TAHUN 2018

Tamin, O. Z. 2017, Perencanaan, Pemodelan \& Rekayasa Transportasi: Teori, Contoh Soal, dan Aplikasi, Bandung, ITB.

Undang-undang Republik Indonesia Nomor 23 Tahun 2007 tentang Perkeretaapian, Jakarta, 2007.

Vuchic, Vukan R.,1981, Urban Public Transportation System and Technology. University of Pensylvania.

Wibowo, Bagio Catur 2003. Analisis Tingkat Kepuasan Pelayanan Umum Prasarana Terminal Rajabasa Kota Bandar Lampung. [Tesis]. Surabaya

Wisnu, Prima, 2018, "Analisis Kinerja Operasional Kereta Api Jurusan JakartaPurwakarta (Studi Kasus Kereta Api Walahar Expres dan Cilamaya Expres)" Vol. 01 No. 01, Juni 2018 